\title{
AMINO ACID METABOLISM OF ASTACUS LEPTODACTYLUS (ESCH.)-II. BIOSYNTHESIS OF THE NON-ESSENTIAL AMINO ACIDS
}

\author{
Willibrordus J. A. van MarrewiJk and Daniel I. Zandee \\ Laboratory of Chemical Animal Physiology, Transitorium 3, 8 Padualaan State University of \\ Utrecht, The Netherlands
}

(Received 11 March 1974)

\begin{abstract}
Incubation of Astacus leptodactylus with U-14 $\mathrm{C}$-glucose or 1-14 $\mathrm{C}$-acetate induced labelling of $\alpha$ - and $\beta$-alanine, aspartic and glutamic acids, glutamine, glycine, proline and serine. No radioactivity was incorporated into arginine, asparagine, histidine, isoleucine, leucine, lysine, ornithine, phenylalanine, taurine, threonine, tyrosine and valine.

2. From the results obtained the biosynthetic pathways for the non-essential amino acids in $A$. leptodactylus are discussed.
\end{abstract}

\section{INTRODUCTION}

IN NUMEROUS dietetic experiments it has been shown that insects need nearly the same essential amino acids as higher animals. For Crustacea data in this field are very rare. The most extensive investigations have been made by Zandee $(1964,1966 a)$ on Astacus astacus. By studying the incorporation of radiocarbon into amino acids from injected $1{ }^{14} \mathrm{C}$-acetate or $\mathrm{U}^{14} \mathrm{C}$-glucose he showed valine, leucine, isoleucine, threonine, lysine, histidine and phenylalanine to be essential. Glycine, alanine, serine, aspartic acid, glutamic acid, tyrosine, proline, hydroxyproline and probably also arginine were shown to be non-essential. Labelling of alanine, aspartic acid, glutamic acid and glutamine from 2-14 $\mathrm{C}$-acetate, $1,4-{ }^{14} \mathrm{C}$-succinate or U-14 C-glucose has been observed in Carcinus maenas (Huggins, 1966) and in Elminius modestus (Boulton et al., 1967). Gilles \& Schoffeniels $(1968 \mathrm{a}, \mathrm{b})$ have reported ${ }^{14} \mathrm{C}$ incorporation into alanine, aspartic acid, glutamic acid, glycine, serine and taurine after incubation of nerve tissue of Homarus vulgaris with $\mathrm{U}^{14} \mathrm{C}$-glucose or $1^{-14} \mathrm{C}$-pyruvate.

On the basis of the relative distribution of radioactivity in alanine, aspartic acid and glutamic acid after incubation of lobster nerve cord with $\mathrm{U}^{14} \mathrm{C}$ glucose, 1-1" $\mathrm{C}$-and 2-14 $\mathrm{C}$-pyruvate, Gilles \& Schoffeniels $(1964 a, b)$ have postulated the existence of a metabolic pathway shunting the citric acid cycle and leading directly to the synthesis of glutamic acid from glucose. Such a pathway has been proposed by Gilles \& Schoffeniels (1969) after incubation experiments with $\mathrm{U}-{ }^{14} \mathrm{C}$-arabinose, showing incorporation of radiocarbon in aspartic acid, glutamic acid and taurine. This pathway would be the one described by Weimberg \& Doudoroff (1965) for Pseudomonas saccharophila, starting from an intermediate of the glucuronate pathway and leading to the formation of 2-ketoglutarate with arabinose and another (unknown) compound as intermediates.

From the isotope distribution in the non-essential amino acids after incubation with ${ }^{14} \mathrm{C}$-labelled precursors, Zandee (1966a) has concluded that the biosynthesis of these amino acids in $A$. astacus generally takes place via metabolic pathways already known for vertebrates and invertebrates. Only for aspartic acid the way of labelling could not be explained by the known synthesis in vertebrates.

In a previous publication we have described the composition of the amino acid pattern in Astacus leptodactylus (van Marrewijk \& Ravestein, 1974). In the present paper incubation experiments of this crayfish with U-14 $\mathrm{C}$-glucose and ${ }^{1-{ }^{14}} \mathrm{C}$-acetate are discussed. The results of these experiments will show which amino acids can be synthesized by $A$. leptodactylus. Moreover, the biosynthetic pathways of these non-essential amino acids are discussed.

\section{MATERIALS AND METHODS}

\section{Animals}

The origin of the crayfishes and the way they were kept in the laboratory have been described elsewhere (van Marrewijk \& Ravestein, 1974). Animals used for experiments were males in the intermolt stage.

\section{Experiments}

Two incubation experiments of $A$. leptodactylus with radioactive compounds were performed.

In the first experiment in January three crayfishes, total weight $259 \mathrm{~g}$, were injected four times with intervals of 
$48 \mathrm{hr}$ with $\mathrm{U}{ }^{14} \mathrm{C}$-glucose (sp. act. $5.0 \mathrm{mCi} / \mathrm{m}$-mole). The dose administered was $0.5 \mu \mathrm{Ci} / \mathrm{g}$ animal at each injection.

In the second experiment in July five crayfishes, total weight $267.5 \mathrm{~g}$, were injected with $1{ }^{14} \mathrm{C}$-acetate (sp. act. $2 \cdot 1 \mathrm{mCi} / \mathrm{m}$-mole). The dose administered was $2 \cdot 0 \mu \mathrm{Ci} / \mathrm{g}$ animal, and the incubation time was $24 \mathrm{hr}$.

The radioactive precursors were administered by intramuscular injection of aqueous solutions in the ventral part of the abdomen. Always less than $50 \mu \mathrm{l} /$ animal was injected.

\section{Incubation of the animals}

Incubations were performed in a closed perspex case filled with water. During the incubation period this water was continuously aerated. The $\mathrm{CO}_{2}$ expired by the animals was trapped in ethanolamine to determine its radioactivity. $\mathrm{CO}_{2}$ dissolved in the water was expelled by acidification with concentrated hydrochloric acid and also trapped in ethanolamine. The temperature of the water was kept at $13-16^{\circ} \mathrm{C}$ by cooling the case in running tap water.

The animals were placed in the case $24 \mathrm{hr}$ before injection. During the incubation the animals were not fed. The incubation period was ended by freezing the animals to death at $-20^{\circ} \mathrm{C}$.

\section{Fractionization of the animals}

The procedures for separating the crayfishes into different classes of chemical compounds have been described elsewhere (de Zwaan \& van Marrewijk, 1973). The following six fractions were prepared:

1. Lipids: phospholipids, neutral lipids and free fatty acids.

2. Free amino acids: all free amino acids, except the strongly acidic cysteic acid, phosphoserine and taurine, which were not bound to the cation exchanging resin.

3. Organic acids and sugar phosphates: intermediates of the citric acid cycle, lactate and pyruvate, and sugar phosphates. Moreover, cysteic acid, phosphoserine and taurine are included in this fraction.

4. Neutral components: including sugars (also glucose, one of the precursors used).

5. Glycogen.

6. Proteins.

\section{Analysis of the amino acids}

Qualitative and quantitative analyses of the free amino acids were performed using an automatic analyser as described in an earlier publication (van Marrewijk \& Ravestein, 1974). Concentrations of the amino acids were calculated with the aid of an integrator (Infotronics, Model CRS 110A).

\section{Measurement of radioactivity}

For direct measurement of the radioactivity of the eluted amino acids, the analytical system was modified according to Schram \& Lombaert (1962). The column eluent was passed continuously through a liquid scintillation counter (Packard 2002). This counter was fitted with a U-shaped flowcell, filled with coated anthracene crystals (Packard Instrument S.A.). With a ratemeter (Packard 280A) and recorder (Philips PR 2500), a continuous record of radioactivity in the eluent was obtained. Subsequently, the resolved amino acids were detected as described previously (van Marrewijk \& Ravestein, 1974).

Other radioactivities were determined with a Nuclear Chicago liquid scintillation counter, Model MKII, equipped with an automatic external standardization.

The scintillation medium used for counting aqueous solutions was composed according to Bray (1960). Carbon dioxide was counted in the ethanolamine scintillation medium according to Jeffay \& Alvarez (1961). Toluene-Omniffuor (NEN Chemicals) was used for counting chloroform-soluble compounds and dry materials after dissolving in Soluene 100 (Packard).

\section{RESULTS AND DISCUSSION}

The results of the two incubation experiments are shown in Table 1. From both precursors approximately 30 per cent of the radioactivity was recovered in $\mathrm{CO}_{2}$ expired. Besides, a considerable amount of radioactivity was liberated as ${ }^{14} \mathrm{CO}_{2}$ by decalcification of the exoskeletons with $\mathrm{HCl}$. This agrees with earlier observations on $A$. astacus by Zandee (1966b), who found a significant fixation of ${ }^{14} \mathrm{CO}_{2}$ in $\mathrm{CaCO}_{3}$ of the exoskeleton during incubation of the crayfish with 1-14C-acetate.

From both precursors only about one-half of the radioactivity administered was recovered (in ${ }^{14} \mathrm{CO}_{2}$ or incorporated in the dry homogenate). The unrecovered half may be accounted for by several reasons:

1. Some leakage of radioactivity from the animal into the water after injection.

Table 1. Radioactivity in $\mathrm{CO}_{2}$ and dry homogenate of $A$. leptodactylus after injection of $\mathrm{U}^{14} \mathrm{C}-\mathrm{glucose}$ (four times with intervals of $48 \mathrm{hr}$ ) and $1{ }^{11} \mathrm{C}$-acetate (one injection, incubation period $24 \mathrm{hr}$ )

\begin{tabular}{|c|c|c|c|c|}
\hline & \multicolumn{2}{|c|}{ U-11C-glucose } & \multicolumn{2}{|c|}{ 1-14C-acetate } \\
\hline & $\mu \mathrm{Ci}$ & $\%$ & $\mu \mathbf{C i}$ & $\%$ \\
\hline $\begin{array}{l}\text { Dose administered } \\
{ }^{14} \mathrm{CO}_{2}-\text { expired }{ }^{*} \\
{ }^{14} \mathrm{CO}_{2} \text {-exoskeleton } \\
\text { Dry homogenate }\end{array}$ & $\begin{array}{r}512 \cdot 4 \\
146 \cdot 0 \\
51 \cdot 4 \\
53 \cdot 3\end{array}$ & $\begin{array}{r}100 \\
28 \cdot 2 \\
9 \cdot 9 \\
10 \cdot 3\end{array}$ & $\begin{array}{r}535 \cdot 0 \\
169 \cdot 0 \\
95 \cdot 2 \\
35 \cdot 0\end{array}$ & $\begin{array}{r}100 \\
31 \cdot 6 \\
17 \cdot 8 \\
6.5\end{array}$ \\
\hline
\end{tabular}

* Including $\mathrm{CO}_{2}$ expelled from the water. 
Table 2. Distribution of radioactivity between the different classes of compounds from A. leptodactylus after injection of $\mathrm{U}^{-14} \mathrm{C}$-glucose (four times with intervals of $48 \mathrm{hr}$ ) and 1 . $14 \mathrm{C}$-acetate (one injection, incubation period $24 \mathrm{hr}$ )

\begin{tabular}{|c|c|c|c|c|}
\hline \multirow{2}{*}{ 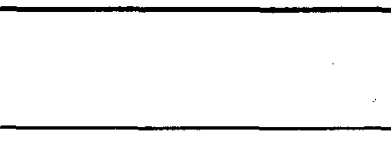 } & \multirow{2}{*}{\multicolumn{2}{|c|}{$\frac{\text { U-16-glucose }}{\text { dis/min } \times 10^{3}}$}} & \multicolumn{2}{|c|}{ 1-14C-acetate } \\
\hline & & & $\mathrm{dis} / \mathrm{min} \times 10^{3}$ & $\%$ \\
\hline $\begin{array}{l}\text { Dry homogenate } \\
\text { Lipids } \\
\text { Glycogen } \\
\text { Proteins } \\
\text { Free amino acids } \\
\text { Neutral components } \\
\text { Organic acids and sugar phosphates }\end{array}$ & $\begin{array}{r}834 \cdot 7 \\
8 \cdot 3 \\
0 \cdot 6 \\
6 \cdot 5 \\
196 \cdot 7 \\
57 \cdot 4 \\
518 \cdot 3\end{array}$ & $\begin{array}{r}100 \\
1.0 \\
<0.1 \\
0.8 \\
23 \cdot 6 \\
6.9 \\
62.0\end{array}$ & $\begin{array}{r}826 \cdot 3 \\
39 \cdot 0 \\
0 \cdot 2 \\
6 \cdot 6 \\
539 \cdot 2 \\
2 \cdot 6 \\
161 \cdot 7\end{array}$ & $\begin{array}{r}100 \\
4.7 \\
<0.1 \\
0.8 \\
65.3 \\
0.3 \\
19.6\end{array}$ \\
\hline
\end{tabular}

2. Excretion by the experimental animals of radioactive compounds into the water during the incubation period.

3. Only soft tissues which could be prepared easily were homogenized: the whole exoskeleton, the legs and claws (including the claw muscle), the mandibular muscle and the gills were excluded.

4. Loss in radioactivity during lyophilization of the homogenate (de Zwaan \& van Marrewijk, 1973).

\section{Distribution of the radioactivity between the different classes of compounds}

Table 2 shows the distribution of radioactivity in the dry homogenate between the different classes of compounds. From ${ }^{14} \mathrm{C}$-glucose nearly two-thirds of the radioactivity was recovered in the organic acids and sugar phosphates, from ${ }^{16} \mathrm{C}$-acetate only onefifth. It is likely that in A. leptodactylus, analogous to Carcinus maenas (Huggins, 1966) and Elminius modestus (Boulton et al., 1967), in the main the sugar phosphates will be labelled from ${ }^{14} \mathrm{C}$-glucose, while primarily in the organic acids ${ }^{14} \mathrm{C}$ will be incorporated from ${ }^{14} \mathrm{C}$-acetate.

From ${ }^{11} \mathrm{C}$-glucose, the labelling of the free amino acids accounted for a fourth part of the radioactivity of the homogenate, whereas from ${ }^{14} \mathrm{C}$-acetate the free amino acids were the highest labelled fraction with two-thirds of the total radioactivity incorporated. The labelling of the neutral components from ${ }^{14} \mathrm{C}$-glucose (7 per cent) is probably partly due to sugars (including unmetabolized ${ }^{14} \mathrm{C}$-glucose). From ${ }^{14} \mathrm{C}$-acetate this fraction was labelled only slightly (less than 1 per cent). The ${ }^{14} \mathrm{C}$-incorporation into lipids was relatively low from both precursors. The labelling of this fraction was several times higher from ${ }^{14} \mathrm{C}$-acetate than from ${ }^{14} \mathrm{C}$-glucose, as may be expected from the central role of acetate in the biosynthesis of lipids. In the proteins less than 1 per cent of the radioactivity was recovered. This suggests a low rate of protein synthesis, since the free amino acids, which account for up to 12 per cent of the total amino acids (i.e. free plus protein-bound) (van
Marrewijk \& Ravestein, 1974), were labelled highly.

Hardly any radioactivity was found in glycogen. Investigating the labelling of glycogen in $A$. astacus at different times after injection of $\mathrm{U}^{1}{ }^{14} \mathrm{C}$-glucose, Zandee (1966b) has found great individual differences in the labelling of glycogen from the hepatopancreas. The glycogen from the walking leg muscle showed the highest labelling $8 \mathrm{hr}$ after injection of the "C-glucose, after which the radioactivity decreased gradually to 5 per cent of its maximum after $192 \mathrm{hr}$. Therefore, the low labelling of glycogen we found in $A$. leptodactylus may not be ascribed simply to a low rate of synthesis.

\section{Distribution of radioactivity in the free amino acid fraction}

Table 3 shows the distribution of radioactivity between the individual free amino acids after the four times $48 \mathrm{hr}$ incubation period with $\mathrm{U}-{ }^{14} \mathrm{C}$ glucose. No radioactivity was found in threonine, valine, isoleucine, leucine, tyrosine, phenylalanine, lysine, histidine and arginine. Probably these amino acids are essential to $A$. leptodactylus, except tyrosine which was shown to be synthesized from phenylalanine in A. astacus (Zandee, 1966a). So the same amino acids which are essential to the rat (Rose, 1938), to the blowfly Calliphora erythrocephala (Sedee, 1961) and to $A$. astacus (Zandee, 1966a) are essential to $A$. leptodactylus too. In arginine, which was shown to be slightly labelled in $A$. astacus (Zandee, 1966a), we found no labelling at all in $A$. leptodactylus. Ornithine, which can be formed from arginine (van Marrewijk \& Ravestein, 1974), was not labelled either.

Besides, no radioactivity was measured in asparagine. This compound occurs in plants, microorganisms and animal tissues as a free amino acid as well as being incorporated into proteins (Meister, 1965). Though the synthesis of asparagine is incompletely understood, the main biosynthetic mechanism seems to be the condensation of ammonia and aspartate (Lehninger, 1970). In $A$. 
Table 3. Composition of the free amino acid fraction from A. Leptodactylus and distribution of radioactivity between the amino acids after injection of $\mathrm{U}-\mathrm{C}$-glucose (four times with intervals of $48 \mathrm{hr}$ )

\begin{tabular}{|c|c|c|c|c|}
\hline & \multirow{2}{*}{ 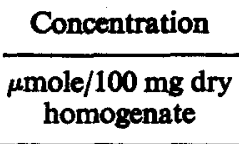 } & \multicolumn{3}{|c|}{ Radioactivity } \\
\hline & & $\mathrm{dis} / \min \times 10^{3}$ & $\begin{array}{c}\% \text { of the } \\
\text { total }\end{array}$ & $\begin{array}{l}\text { dis/min per } \\
\mu \text { mole } \times 10^{8}\end{array}$ \\
\hline Aspartic acid & 0.24 & $1 \cdot 2$ & 0.7 & $5 \cdot 1$ \\
\hline Threonine & 1.29 & - & - & - \\
\hline Serine & 1.65 & $2 \cdot 5$ & $1 \cdot 4$ & 1.5 \\
\hline Asparagine & 0.77 & - & - & - \\
\hline Glutamic acid & $1 \cdot 38$ & $14 \cdot 5$ & $8 \cdot 1$ & $10 \cdot 5$ \\
\hline Glutamine & 2.73 & 30.0 & $16 \cdot 8$ & $11 \cdot 0$ \\
\hline Proline & 0.94 & 3.5 & $2 \cdot 0$ & 3.7 \\
\hline Glycine & 13.00 & $9 \cdot 5$ & $5 \cdot 3$ & 0.7 \\
\hline$\alpha$-Alanine & 4.25 & $87 \cdot 4$ & 49.0 & $20 \cdot 6$ \\
\hline Cystine & $0 \cdot 13$ & $0.5^{*}$ & $0.3^{*}$ & 3.9* \\
\hline Valine & 0.76 & - & - & - \\
\hline Methionine & 0.44 & $1 \cdot 0^{*}$ & $0.6^{*}$ & $2 \cdot 3^{*}$ \\
\hline Isoleucine & 0.40 & - & - & - \\
\hline Leucine & 0.82 & - & - & - \\
\hline Tyrosine & 0.65 & 一 & - & - \\
\hline Phenylalanine & 0.49 & - & - & - \\
\hline$\beta$-Alanine & $6 \cdot 39$ & $28 \cdot 0$ & $15 \cdot 7$ & 4.4 \\
\hline Ornithine & 0.77 & - & - & - \\
\hline Lysine & 1.60 & - & - & - \\
\hline Histidine & 0.78 & - & - & - \\
\hline Arginine & $7 \cdot 13$ & - & - & - \\
\hline Total & $46 \cdot 61$ & $178 \cdot 1$ & 99.9 & - \\
\hline
\end{tabular}

- Whether this radioactivity actually represents a labelling of cystine and methionine is not clear.

Table 4. Concentration and radioactivity of the free amino acids labelled $24 \mathrm{hr}$ after injection of $1 .{ }^{14} \mathrm{C}$ acetate into $A$. leptodactylus

\begin{tabular}{|c|c|c|c|c|}
\hline \multirow[b]{2}{*}{ Amino acid } & \multirow{2}{*}{ 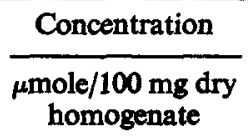 } & \multicolumn{3}{|c|}{ Radioactivity } \\
\hline & & $\mathrm{dis} / \mathrm{min} \times 10^{3}$ & $\begin{array}{l}\% \text { of the } \\
\text { total }\end{array}$ & $\begin{array}{l}\text { dis/min per } \\
\mu \mathrm{mole} \times 10^{3}\end{array}$ \\
\hline Aspartic acid & 3.9 & $18 \cdot 2$ & $3 \cdot 7$ & $4 \cdot 7$ \\
\hline Serine & $5 \cdot 3$ & $3 \cdot 2$ & 0.6 & 0.6 \\
\hline Glutamic acid & 8.9 & 251.9 & 51.8 & $28 \cdot 3$ \\
\hline Glutamine & $5 \cdot 3$ & $108 \cdot 0$ & $22 \cdot 2$ & $20 \cdot 4$ \\
\hline Proline & 7.0 & 5.6 & $1 \cdot \overline{1}$ & 0.8 \\
\hline Glycine & $12 \cdot 0$ & $6 \cdot 0$ & 1.2 & 0.5 \\
\hline$\alpha$-Älanine & $9 \cdot 5$ & $93 \cdot 7$ & $19 \cdot 2$ & 9.9 \\
\hline$\beta$-Alanine & $0 \cdot 3$ & 0.2 & $<0.1$ & 0.6 \\
\hline
\end{tabular}

leptodactylus, however, no synthesis of asparagine took place neither from ${ }^{14} \mathrm{C}$-glucose (Table 3) and ${ }^{14} \mathrm{C}$-acetate (Table 4) nor from ${ }^{14} \mathrm{C}$-aspartate (as will be shown in a later publication). These results suggest that the crayfish is probably unable to synthesize asparagine. From our experiments it is not clear whether asparagine occurs in $A$. leptodactylus only as a free amino acid derived from the food or is also incorporated into proteins. In the latter case asparagine would be essential to the crayfish.

Labelling was observed in aspartic acid, serine, glutamic acid, glutamine, proline, glycine, $\alpha$ - and $\beta$-alanine, so these amino acids may be considered to be non-essential to $A$. leptodactylus. Besides on the radiogram some radioactivity was found on the place of cystine and methionine (Fig. 1). However, it could not be stated with certainty that this radioactivity could be accounted for by these amino acids, since on elution of cystine and methionine-during and immediately after the breakthrough of the second buffer, respectively - other components present in the amino acid fraction may be eluted at the same time.

Figure 1 was obtained by a direct analysis of the freeze-dried ethanol extract of the homogenate (de 


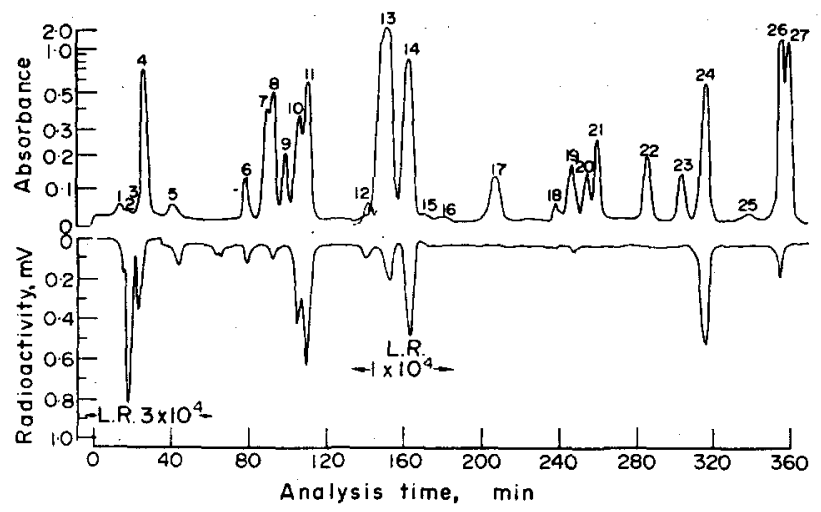

Fig. 1. Distribution of radioactivity between the free amino acids of $A$. leptodactylus after incubation with $\mathrm{U}^{11} \mathrm{C}$-glucose. The absorbance was measured at $570 \mathrm{~nm}$ (for proline at $440 \mathrm{~nm}$ ). The ratemeter was adjusted to a linear range (L.R.) of $3 \times 10^{3}$, except where indicated otherwise in the figure. 1, Phosphoserine and/or cysteic acid; 2 , unknown; 3, unknown; 4, taurine; 5 , urea( ?); 6, aspartic acid; 7, threonine; 8 , serine; 9 , asparagine; 10 , glutamic acid; 11, glutamine; 12, proline; 13 , glycine; 14, $\alpha$ alanine; $15, \alpha$-aminoadipic acid (?); 16, $\alpha$-amino-n-butyric acid; 17 , valine; 18, cystine; breakthrough second buffer; 19, cystathionine +methionine; 20, isoleucine; 21 , leucine; 22, tyrosine; 23, phenylalanine; $24, \beta$-alanine; $25, \beta$-aminoisobutyric acid (?); 26 and 27 , LiOH breakthrough and basic amino acids.

Zwaan \& van Marrewijk, 1973). The large amount of radioactivity measured during the elution of the strongly acidic ninhydrin-positive components (peaks 1,2 and 3) represents the labelling of the organic acids and sugar phosphates which also are present in the fraction analysed. Figure 1 shows that no radioactivity was incorporated into taurine. In other incubation experiments with ${ }^{14} \mathrm{C}$-labelled precursors $\left(1-{ }^{14} \mathrm{C}\right.$-acetate, 1 - or ${ }^{2-14} \mathrm{C}$-pyruvate, $\mathrm{NaH}^{14} \mathrm{CO}_{3}$ ) no labelling of taurine was observed either. From this it may be concluded that $A$. leptodactylus is unable to synthesize taurine from the precursors mentioned. This conclusion disagrees with the results of Gilles \& Schoffeniels (1968a, b), who reported a high labelling of taurine from $\mathrm{NaH}^{14} \mathrm{CO}_{3}$ in the nerve cord of Homarus vulgaris, while from U-14C-glucose taurine was found to be the highest labelled amino acid.

Half of the radioactivity in the free amino acids was incorporated into $\alpha$-alanine. Pyruvate derived from U. ${ }^{14} \mathrm{C}$-glucose will be highly labelled and consequently also $\alpha$-alanine that arises from it by transamination (Zandee et al., 1958).

The labelling of glutamic acid and glutamine together accounts for one-quarter of the radioactivity, with an absolute activity of glutamine which is twice as high as a specific activity which is as high as the activity of glutamic acid. The high rate of synthesis of both amino acids is probably closely connected with their functional importance in the metabolism. Glutamic acid plays a central role in most transamination reactions and is a precursor for various compounds (e.g. several other amino acids), while glutamine, apart from its role in the excretion of ammonia (van Marrewijk, 1972; van Marrewijk \&
Ravestein, 1974), functions as an aminor donor in the synthesis of $\mathrm{NAD}^{+}$and the purine ring (Meister, 1965). Moreover, both the $\alpha$-amino and the $\gamma$-amide group of glutamine may participate in the amination of keto acids, as has been shown in guinea-pigs (O'Donovan \& Lotspeich, 1969).

A remarkably high labelling was found in $\beta$ alanine (nearly 16 per cent). Also the concentration of this amino acid was high; only glycine and arginine were more abundant. This high concentration, combined with the substantially lower concentrations we reported before (van Marrewijk \& Ravestein, 1974), emphasizes the large variation in the concentration of this amino acid in $A$. leptodactylus as has been shown by Partmann (1971). The biosynthesis of $\beta$-alanine in $A$. leptodactylus will be discussed in more detail in a later publication.

Table 4 shows which amino acids were labelled after a $24-\mathrm{hr}$ incubation period with $1-^{14} \mathrm{C}$-acetate. From this precursor radioactivity was incorporated in the same amino acids as from $\mathrm{U}^{14} \mathrm{C}$-glucose. However, no radioactivity was measured on the elution place of cystine and methionine; this in contrast to the U-14C-glucose incubation (Fig. 1, Table 3). A high labelling of glutamine was measured, resulting in a specific activity of the same magnitude as that found for glutamic acid. Nearly threequarters of the total radioactivity in the amino acids was recovered in glutamic acid plus glutamine. This may be attributed to the short pathway from acetate to 2-ketoglutarate, the direct precursor of glutamic acid, via the citric acid cycle. In $A$. astacus, $24 \mathrm{hr}$ after the injection of $1{ }^{14} \mathrm{C}$-acetate, approximately 60 per cent of the radioactivity in the non-essential amino acids was recovered in glutamic acid (in- 
cluding glutamine) (Zandee, 1964). Also a very high labelling of glutamic acid and glutamine ( 82 per cent) was reported for Elminius modestus $6 \mathrm{hr}$ after the injection of ${ }^{2 \cdot 14} \mathrm{C}$-acetate (Boulton et al., 1967).

The labelling of proline can be understood by assuming its biosynthesis to take place from glutamic acid, as was suggested also for Calliphora erythrocephala (Sedee, 1961) and A. astacus (Zandee, 1966a). In this pathway glutamic- $\gamma$-semialdehyde is a key intermediate, as has been shown in mammals (Stetten, 1951).

A fifth part of the total radioactivity was incorporated into $\alpha$-alanine. This high labelling suggests an active decarboxylation of malate and/or oxaloacetate. From $1{ }^{14} \mathrm{C}$-acetate these citric acid cycle intermediates will be labelled in both carboxyl carbons, by randomization of the label in succinate or fumarate. Decarboxylation will result in the formation of $\mathrm{C}_{1}$-labelled phosphoenolpyruvate or pyruvate, from which $C_{1}$-labelled $\alpha$-alanine can arise by transamination. Also the labelling of serine can be understood from the decarboxylation of oxaloacetate. The resultant phosfoenolpyruvate will be transformed to the glycolysis intermediate 3-phosphoglycerate, which is a precursor of serine. The labelling of glycine may be explained by its synthesis from serine. Another explanation for the high labelling of $\alpha$-alanine might be its formation by $\beta$ decarboxylation of aspartate, as has been reported for Homarus vulgaris (Gilles \& Schoffeniels, 1966). Research on the (de)carboxylation reactions mentioned and their relative importance in the intermediary metabolism of $A$. leptodactylus is in progress.

The labelling of $\beta$-alanine from $1{ }^{14} \mathrm{C}$-acetate after an incubation time of $24 \mathrm{hr}$ was remarkably low (less than 0.1 per cent), as compared with the high radioactivity of this amino acid after a four times $\mathbf{4 8}$ $\mathrm{hr}$ incubation period with $\mathrm{U}-{ }^{14} \mathrm{C}$-glucose (nearly 16 per cent). Also the concentration of $\beta$-alanine was very low, whereas most other amino acids showed substantially higher concentrations in the ${ }^{14} \mathrm{C}$ acetate experiment than after incubation with ${ }^{14} \mathrm{C}$ glucose. The latter seems to be a much better precursor for $\beta$-alanine than acetate.

\section{SUMMARY}

In order to investigate the biosynthesis of amino acids in the crayfish, $A$. leptodactylus, incubation experiments were performed with $\mathrm{U}-{ }^{14} \mathrm{C}$-glucose (injected four times with intervals of $48 \mathrm{hr}$ ) and ${ }^{1-14} \mathrm{C}$-acetate (one injection, incubation period 24 hr).

Approximately one-third of the U-14 $\mathrm{C}$-glucose injection and one-half of the ${ }^{1-14} \mathrm{C}$-acetate was oxidized to $\mathrm{CO}_{2}$. A considerable part of this $\mathrm{CO}_{3}$ was fixed in $\mathrm{CaCO}_{3}$ of the exoskeleton.

With U-14C-glucose as a precursor, 62 per cent of the radioactivity incorporated was recovered in the organic acids and sugar phosphates and about 24 per cent in the free amino acids. From ${ }^{1-14} \mathrm{C}$-acetate these percentages were 20 and 65 , respectively. A low labelling was found in the neutral components, lipids, proteins and glycogen.

From both precursors ${ }^{14} \mathrm{C}$ was incorporated into the protein amino acids and $\alpha$-alanine, aspartic acid, glutamic acid, glutamine, glycine, proline and serine, and the non-protein amino acid $\beta$-alanine, so these amino acids may be considered to be non-essential to $A$. leptodactylus. No ${ }^{14} \mathrm{C}$-incorporation took place into the protein amino acids arginine, histidine, isoleucine, leucine, phenylalanine, threonine, tyrosine, valine, and probably cystine and methionine. Nor did we find any radioactivity in asparagine, ornithine and taurine.

With the exception of $\beta$-alanine, the ${ }^{14} \mathrm{C}$-incorporation into the non-essential amino acids from the labelled precursors can be explained by their synthesis from glycolytic and citric acid cycle intermediates.

The labelling of $\alpha$-alanine, serine and glycine from ${ }_{1-14} \mathrm{C}$-acetate suggests an active decarboxylation of oxaloacetate and possibly also malate and aspartate.

The high concentration and labelling of $\beta$-alanine after incubation with $\mathrm{U}-{ }^{14} \mathrm{C}$-glucose as compared to the ${ }^{1-14} \mathrm{C}$-acetate incubation suggests that glucose is a much better precursor to $\beta$-alanine synthesis than acetate.

Acknowledgements-The authors are much indebted to Mr. H. J. L. Ravestein for his technical assistance.

\section{REFERENCES}

Boulton A. P., Hugains A. K. \& Munday K. A. (1967) Intermediary metabolism in the barnacle Elminius modestus. Life Sci. 6, 1293-1298.

Bray G. A. (1960) A simple efficient scintillator for counting aqueous solutions in a liquid scintillation counter. Analyt. Biochem. 1, 279-285.

GILles R. \& Schopfeniels E. (1964a) La synthèse des acides aminés de la chaîne nerveuse ventrale du homard. Biochim. biophys. Acta 82, 518-524.

Gilles R. \& Schoffeniels E. (1964b) Action de la vératrine, de la cocaine et de la stimulation électrique sur la synthèse et sur le pool des acides aminés de la chaine nerveuse ventrale du homard. Biochim. biophys. Acta 82, 525-537.

GILles R. \& SchoffenIRLs E. (1966) Décarboxylation des acides aspartique et oxaloacétique chez le homard et l'écrevisse. Bull. Soc. chim. biol. 48, 397-417.

Gilles R. \& Schoffeniels E. (1968a) Fixation de ${ }^{14} \mathrm{CO}_{2}$ par les acides aminés de la chaine nerveuse ventrale du Crustacé Homarus vulgaris M. Edw. Archs int. Physiol. Biochim. 76, 441-451.

Gilles R. \& SCHOFFENIELS E. (1968b) Influence du $\mathrm{NH}_{4} \mathrm{Cl}$ et du sulfate de vératrine sur la synthèse et le pool des acides aminés au niveau de la chaine nerveuse ventrale de deux Crustaces (Homarus vulgaris M. Edw. et Astacus fluviatilis F.). Archs int. Physiol. Biochim. 76, $452-464$. 
Gilles R. \& Schoffeniels E. (1968) Metabolism of arabinose in the ventral nerve cord of the lobster Homarus vulgaris (M. Edw.). Comp. Biochem. Physiol. 28, 1145-1152.

Hugoins A. K. (1966) Intermediary metabolism in Carcinus maenas. Comp. Biochem. Physiol. 18, 283290.

JefFay H. \& Alvarez J. (1961) Liquid scintillation counting of carbon-14. Use of ethanolamine-ethylene glycol monomethyl ether-toluene. Analyt. Chem. 33, 612-615.

LEHNINGER A. L. (1970) Biochemistry. Worth, New York.

Meister A. (1965) Biochemistry of the Amino Acids. Academic Press, New York.

O'DONOVAN D. J. \& LotsPeICh W. D. (1969) The role of the amide group of glutamine in renal biosynthesis of amino acids. Enzymologia 6, 301-312.

PARTMANN W. (1971) Reststickstoff-Substanzen in der Scharen- und Schwanz-muskulatur von Astacus leptodactylus Esch. Archs Fish. Wiss. 22, 103-109.

Rose W. C. (1938) The nutritive significance of the amino acids. Physiol. Rev. 18, 109-136.

SCHRAM E. \& LOMBaERT R. (1962) Determination of tritium and carbon-14 in aqueous solution with anthracene powder. Analyt. Biochem. 3, 68-74.

SedeE PH. D. J. W. (1961) Intermediary metabolism in aseptically reared blowfly larvae, Calliphora erythrocephala (Meig.)-II. Biosynthesis of fatty acids and amino acids. Archs int. Physiol. Biochim. 69, 295-309.

STETTEN M. R. (1951) Mechanism of the conversion of ornithine into proline and glutamic acid in vivo. $J$. biol. Chem. 189, 499-507.
WenMERg R. \& DOUDOROFF M. (1955) The oxidation of L-arabinose by Pseudomonas saccharophila. J. biol. Chem. 217, 607-624.

VAN MARREWUJK W. J. A. (1972) The amino acid metabolism of Astacus leptodactylus Esch. Ph.D. thesis, State University of Utrecht.

Van MarrewiJk W. J. A. \& Ravestenn H. J. L. (1974) Amino acid metabolism of Astacus leptodactylus Esch.-I. Composition of the free and protein-bound amino acids in different organs of the crayfish. Comp. Biochem. Physiol. 47B, 531-542.

ZANDEE D. I. (1964) Metabolism in Astacus astacus (L.) and some other Arthropoda. Ph.D. thesis, State University of Utrecht.

ZaNDEE D. I. (1966a) Metabolism in the crayfish Astacus astacus (L.)-I. Biosynthesis of amino acids. Archs. int. Physiol. Biochim. 74, 35-44.

ZANDEE D. I. (1966b) Metabolism in the crayfish Astacus astacus (L.)-II. The energy-yielding metabolism. Archs int. Physiol. Biochim. 74, 45-57.

ZANDEE D. I., NuKaMp H. J., ROOSHEROR I., DE WAART J., Sedee Ph. D. J. W. \& VoNk H. J. (1958) Transaminations in invertebrates. Archs int. Physiol. Biochim. 66, 220-227.

De ZwaAn A. \& VAN MarrewiK W. J. A. (1973) Anaerobic glucose degradation in the sea mussel Mytllus edulis L. Comp. Biochem. Physiol. 44B, 429-439.

Key Word Index-Amino acid metabolism; biosynthesis of amino acids; essential and non-essential amino acids; Astacus leptodactylus; crayfish; crustaceans. 